\title{
Análise e avaliação ao funcionamento dos clusters em Portugal reconhecidos pelo QREN
}

\section{Analysis and evaluation of clusters in Portugal recognized by NSRF}

\author{
Carla Alexandra Antunes-Ferreira* \\ Maria Manuela Santos-Natário* \\ Ascensáo Maria Martins-Braga*
}

\begin{abstract}
The objective of this study is to analyze Portugal clusters recognized by the Operational Programme Competitiveness Factors within the scope of the National Strategic Reference Framework 2007-2013. It is intended through the study of indicators of geographical concentration measures, as well as the application of a questionnaire to examine whether the eight recognized clusters foreshadow and work with the necessary characteristics for the cluster classification. It is concluded that two clusters are assumed as cluster and two clusters have interaction links/more meaningful cooperation. Moreover, results show that only one cluster is functioning at its fullest while cluster.
\end{abstract}

Keywords: clusters, regional development, European policies.

\section{Resumo}

O objetivo deste trabalho é analisar os clusters de Portugal reconhecidos pelo Programa Operacional Fatores de Competitividade, no âmbito do Quadro de Referência Estratégica Nacional, entre 2007-13. Pretende-se através do estudo de indicadores que constituem medidas de concentração geográfica, bem como, da aplicação de um Questionário, analisar se os oito clusters reconhecidos, prefiguram, funcionam com as características necessárias para a classificação de cluster. Conclui-se que dois clusters funcionam com características de cluster e dois clusters apresentam ligações de interação/cooperação significativas. Conclui-se, ainda, que apenas um cluster está a funcionar na sua plenitude enquanto cluster.

Palavras-chave: clusters, desenvolvimento regional, política europeia.

* Instituto Politécnico da Guarda, correos-e: ferreira_karlla@hotmail.com,m.natario@ipg.pt, sbraga@ipg.pt 


\section{Introduçáo}

A importância dos clusters reside nas suas características específicas que aumentam o sucesso das empresas face à competitividade contribuindo para a geração de riqueza e de emprego nas regiōes onde atuam. O conceito de cluster assume importância enquanto centro de desenvolvimento, de diversificação e de inovação para impulsionar o seu crescimento (Pereira, 2011). Constituídos, em geral, por pequenas empresas, os clusters proporcionam, entre outros, o surgimento de oportunidades de trabalho e o dinamismo de inovaçóes.

Para Neto (2000) os clusters levam as pequenas e médias empresas (PME) a desenvolver atividades que isoladamente náo conseguiriam e, com isso, competir globalmente. Para Roelandt e Hertog (1999) um dos benefícios proporcionados pelos clusters, por oposição às relações horizontais focadas em abordagens sectoriais tradicionais, está relacionado com as relaçôes verticais entre empresas diferentes, a interdependência sinérgica (as relaçóes entre fornecedores, principais produtores e utilizadores) e as interaçóes entre empresas e indústrias em termos de tecnologia, informaçôes, competências, marketing e necessidade dos utilizadores.

Face ao exposto, o objetivo deste estudo consiste em analisar os diferentes clusters de Portugal reconhecidos pelo Programa Operacional Fatores de Competitividade (Compete) no âmbito do Quadro de Referência Estratégica Nacional (QREN), para o período 2007-13, e inserido na política da União Europeia (UE) para este período. Pretende-se através do estudo de indicadores que constituem medidas de concentração geográfica, bem como, da aplicação de um Questionário, analisar se os oito clusters reconhecidos, prefiguram, funcionam com as características necessárias para a classificação de cluster.

O estudo está estruturado em cinco pontos. No ponto 1, efetua-se a contextualizaçáo do conceito de clusters. No ponto 2, efetua-se o enquadramento dos clusters reconhecidos em Portugal, no âmbito das políticas europeias e apresenta-se uma breve caracterização dos mesmos. No ponto 3 , apresenta-se uma proposta metodológica para a identificação dos clusters. Posteriormente, no ponto 4, será apresentada a análise e discussão de resultados alcançados. Por fim, apresentam-se as conclusóes alcançadas, as limitações e as perspetivas de investigação futuras.

\section{Contextualizaçáo dos clusters}

Os contributos de Marshall (1890) com o conceito de distritos industriais, constituíram a base fundamental para o conceito de cluster ao evidenciar 
que a produção em grande escala se torna mais eficiente se houver um aglomerado espacial de um elevado número de empresas numa determinada área que, articulada com economias externas, associadas à aprendizagem, inovação e aumento da especialização, induz à competição que vai aumentar a eficiência e, consequentemente, a capacidade competitiva dessas empresas. A revitalização dos distritos industriais Marshallianos e foi retomada nas obras de Becattini (1979; 1994) e Becattini et al. (2002), que deram um impulso ao desenvolvimento do conceito e contribuíram para uma maior consolidação das bases do cluster. Estes autores consideram que os distritos industriais são entendidos como entidades sócio-territoriais ancoradas num território, que beneficiam de uma comunidade aberta e ativa, de uma cultura e valores comuns, capaz de desenvolver e organizar um sistema de relaçóes entre os atores locais.

Além disso, a especialização industrial das regiōes, como resultado da globalização, implica modificaçóes na organização da atividade económica e na capacidade de produzir e sustentar indústrias que possam ser globalmente competitivas. Neste contexto, o conceito de cluster assume importância crescente como centro de desenvolvimento, inovação e diversificação industrial, permitindo aumentar a competitividade das indústrias aí estabelecidas.

Efetivamente o caráter dominante da globalização na economia mundial com implicaçóes na uniformização de bens, serviços, trabalho, capital e muitas vezes também de preços corrobora a importância do desenvolvimento dos clusters (Pereira e Fernandes, 2006). A importância do cluster reside, também, nas características específicas que garantem o sucesso dessas empresas face à competitividade, às exportaçôes, bem como à criação de emprego e de riqueza. Os clusters não só promovem a competição, mas também estimulam a cooperação (Enright, 2001), desencadeando efeitos externos e interaçóes entre diferentes agentes localizados próximos uns dos outros (Fernandes e Lima, 2006).

A essência do cluster está na criação de capacidades produtivas, especializadas dentro de regiōes para a promoção do seu desenvolvimento económico, ambiental e social (Haddad,1999). Além disso, segundo Porter (1998), a influência e a eficiência de clusters na economia contribuem para o desenvolvimento da organização industrial, da competição e da vantagem competitiva localizada. Assim, os clusters assumem grande notoriedade no estudo da dinâmica de competitividade das empresas e dos territórios. A tabela 1 sintetiza algumas definiçóes de cluster.

Não obstante a variedade de definiçóes e tipos de cluster e a falta de uma definição clara das condiçóes e indicadores de cluster (Cotright, 2006) existe algum consenso no que diz respeito às características de um cluster e às condiçôes necessárias e suficientes para a sua constituição. A aglome- 
ração e a interação são algumas das características que tanto Simmie (2004) como Akgungor (2006) defenderam que deveriam estar presentes num cluster. A aglomeração significa concentração geográfica de uma indústria e atividades. A interação entende-se como a relaçáo competitiva-cooperativa que se estabelece entre os atores locais, o que leva a melhorar o desempenho em termos de geraçáo de emprego, de produtividade e de transferência de conhecimento (Gordon e McCann, 2000). Deste modo, verifica-se que o cluster permite ganhos que vão além dos ganhos decorrentes da simples aglomeração.

Para Russo (2000), o que caracteriza uma estrutura económica definida como cluster é:

- A proximidade, onde as empresas ao terem um contacto direto beneficiam da propagaçáo de conhecimento, do desenvolvimento do capital humano, da circulação física e de infraestruturas comuns;

- A flexibilidade, de forma a existir uma adaptação das empresas às mudanças das circunstâncias externas e internas e a responderem aos estímulos da inovação, que são favorecidos por um ambiente competitivo;

- Pequenas e Médias Empresas, dado que estas empresas apresentam um maior grau de flexibilidade, que é decisivo para a adaptação dos clusters a um ambiente em constante mudança e a questôes ecológicas;

- A eficiência, que é uma característica importante para o desenvolvimento do produto final, para uma qualidade mais aperfeiçoada e para dar melhor resposta às condiçóes do mercado;

- A cooperação que envolve uma relação baseada na colaboração entre empresas, no sentido de alcançar objetivos comuns, utilizando métodos mais ou menos consensuais;

- A competitividade, que se baseia na capacidade de satisfazer as necessidades e expectativas pretendidas, com o objetivo de manter o ritmo de inovação.

Jackson e Murphy (2006) apontam, ainda, mais algumas características dos clusters como por exemplo: partilha dos mesmos valores de ética empresarial, liderança privada, grande envolvimento dos participantes do cluster, forte apoio institucional, apoio nas relações pessoais e, por fim, os autores referem que os clusters se caracterizam por ciclos de vida. Christensen et al. (2002) realçam outras características como: a contínua inovação, a rápida difusão da tecnologia, as elevadas taxas de formação de novas atividades e a diferenciação de produtos e serviços especializados. Pereira e Fernandes (2006) apontam ainda que: 


\section{Tabela 1}

\section{Definiçóes de cluster}

\begin{tabular}{|c|c|}
\hline Autor & Definição \\
\hline Porter (1998) & $\begin{array}{l}\text { Concentraçôes geográficas de determinados setores de ativi- } \\
\text { dades e organizaçôes, de fornecedores especializados, de } \\
\text { clientes e de outras redes de instituiçóes. }\end{array}$ \\
\hline $\begin{array}{l}\text { Organização para a Coo- } \\
\text { peraçáo e Desenvolvi- } \\
\text { mento Econó mico } \\
\text { (OCDE,1999) }\end{array}$ & $\begin{array}{l}\text { Redes de produção de empresas fortemente interdependen- } \\
\text { tes (incluindo fornecedores especializados) ligados entre si } \\
\text { numa cadeia de produçáo de valor acrescentado e alguns } \\
\text { integram alianças entre empresas, universidades, institutos } \\
\text { de investigaçáo e clientes. }\end{array}$ \\
\hline Suzigan et al. (2003) & $\begin{array}{l}\text { Sistemas locais de produção, ou seja, aglomerados de agentes } \\
\text { económicos, políticos e sociais, localizados num mesmo } \\
\text { território, que apresentam vínculos consistentes de articula- } \\
\text { ção, interaçáo, cooperação e aprendizagem. Incluem não só } \\
\text { empresas (produtoras de bens e serviços finais, fornecedoras } \\
\text { de inputs e equipamentos, prestadoras de serviços, comer- } \\
\text { cializadoras, clientes e as suas várias formas de representaçáo } \\
\text { e associação), mas também outras instituiçóes públicas e } \\
\text { privadas direcionadas para a formação e especialização de } \\
\text { recursos humanos, pesquisa, desenvolvimento e engenharia, } \\
\text { promoção e financiamento. }\end{array}$ \\
\hline Silva (2004) & $\begin{array}{l}\text { Concentraçáo geográfica de conjuntos produtivos, seja de } \\
\text { empresas, indústrias, cadeias produtivas, setores ou atividades } \\
\text { económicas que agreguem conhecimento, capital físico ou } \\
\text { capital humano. }\end{array}$ \\
\hline Cotright (2006) & $\begin{array}{l}\text { Grupo de empresas que estabelecem ligaçôes com os agentes } \\
\text { económicos e instituiçóes, localizadas próximas umas das } \\
\text { outras, podendo tirar proveito dessa proximidade. }\end{array}$ \\
\hline $\begin{array}{l}\text { Fernandes e Lima } \\
(2006)\end{array}$ & $\begin{array}{l}\text { Concentrações espaciais de atividades económicas sectorial- } \\
\text { mente especializadas que realizam bastante comércio entre } \\
\text { si, expressando a importância da dimensão espacial para o } \\
\text { desenvolvimento económico. Não é meramente uma simples } \\
\text { concentração de agentes económicos independentes, na } \\
\text { medida em que é necessário haver uma forte intensidade das } \\
\text { relaçóes entre as empresas que se encontram no interior da } \\
\text { aglomeração. }\end{array}$ \\
\hline
\end{tabular}

Fonte: elaboração própria.

- Um cluster não é estático e não tem fronteiras fixas, o que permite que as empresas pertencentes ao cluster estabeleçam ligaçôes com as entidades exteriores ao cluster e que a natureza das relaçóes estabelecidas com as entidades sejam altamente dinâmicas e estejam em constante evolução. As empresas que compóem um cluster 
estabelecem relaçóes de cooperação e de competição e, maioritariamente, seguem uma organizaçáo flexível e são independentes umas em relação às outras.

- Um cluster apresenta diferentes etapas de desenvolvimento, que estão relacionadas com a criação de um cluster, o desenvolvimento de um cluster criado ou já existente e com a análise de segmentação de clusters que são potenciais ou emergentes.

- A abordagem do desenvolvimento de um cluster deve ser baseada na atividade económica presente, utilizando a linguagem usual das empresas, bem como o seu estilo empresarial (Lyon e Atherton, 2000). A compreensão dos processos de clustering permite apoiar o desenvolvimento de um cluster, se este for baseado no crescimento já existente e não na adaptação de modelos de outras indústrias, de outras localizaçóes ou de exemplos retirados de estudos de caso que são, muitas vezes, interpretados erradamente como modelos possíveis de transferir. O processo clustering permite verificar o modo como as empresas podem aprender, cooperar e harmonizar-se localmente ao mesmo tempo que competem.

Estudos mais recentes têm criticado esta abordagem dos clusters que sendo aplicada num contexto com características específicas é de certa forma limitativa. São indicadas como críticas, entre outras, a má utilização do conceito e multiplicidade de tipologias e classificaçóes (Malmberg, 2003), a forma como se atinge a competitividade (Martin e Sunley, 2003; Kitson et al. 2004), as divergências entre a teoria e as evidências empíricas (Malmberg, 1997; Maskell e Malmberg, 1999; Malmberg e Maskell, 2002). Outras abordagens foram surgindo, como a abordagem de Sistemas de Inovação (Edquist, 1997; Carlsson et al., 2002); Sistemas Setoriais de Inovação (Malerba, 2004); abordagem de Sistemas Tecnológicos de Inovação (Carlsson, 1995) e o Modelo Hibrido (Silvestre, 2006), onde são importantes as fontes internas e externas de conhecimento para um dado aglomerado (Bell e Albu, 1999).

\section{Enquadramento dos clusters reconhecidos em Portugal no âmbito das políticas europeias}

A Estratégias de Eficiência Coletiva (EEC), enquadrada no âmbito do Quadro de Referência Estratégica Nacional (QREN) assumiu-se como uma política pública de apoio à clusterização em Portugal para acompanhar as tendências internacionais. Neste seguimento, reconhece a importância do papel dos clusters enquanto plataformas de inovação aberta, catalisa- 
doras do acesso e partilha de conhecimento e do fomento de práticas colaborativas (entre as entidades da tripla hélice que integram os seus ecossistemas, nomeadamente entre empresas, instituiçóes de ensino superior e instituiçóes públicas) (Etzkowitz, 2003), em fases iniciais dos processos de inovação, investigação e desenvolvimento tecnológico e de internacionalização. Esta política reconhece, em consequência, a importância dos processos de clusterização para o reforço da competitividade e da eficiência industrial, para a promoção da inovação e para a transformação económica, atendendo à procura de mercado e aos desafios das sociedades.

Em termos históricos, a política de clusterização encontra as suas raízes nos trabalhos de Porter (1994), realizados em Portugal na primeira metade da década de 90 (e num conjunto de medidas, parcelares e pontuais), obtendo assim uma expressividade mais significativa com o surgimento do QREN 2007-2013. O trabalho de Porter (1994): Construir Vantagens Competitivas em Portugal, permitiu identificar as áreas em que Portugal apresentava vantagens competitivas, assim como os principais desafios colocados ao seu desenvolvimento, tendo concluído sobre a existência de alguns clusters a desenvolver (produtos florestais, têxteis, vestuário e mobiliário) e de clusters desenvolvidos e geograficamente concentrados (cortiça, calçado, pedras ornamentais e moldes).

Em 2002, a política de clusterização parece reforçar a sua importância em termos conceptuais, com o Programa Integrado de Apoio à Inovação (Proinov), em particular no contexto do seu apelo ao desenvolvimento de clusters de inovação em áreas chave. No âmbito do Proinov (2002), foram identificados diferentes mega clusters, ou seja, conjuntos de atividades distintas recorrendo a competências básicas e complementares e podendo explorar vantagens de articulação em rede (nomeadamente alimentação, habitat, moda, lazer, mobilidade, saúde, serviços pessoais, informação e entretenimento) e vários clusters efetivos ou potenciais. A prioridade seria promover a identificação e diagnóstico das regiōes em declínio económico efetivo e potencial, o apuramento das vocaçóes económicas, recursos específicos e vantagens relativas por região (indústrias, serviços, turismo, etc.), a identificação de âncoras de desenvolvimento (universidades, politécnicos, áreas de localização empresarial, médias/ grandes empresas, etc.), a adoção consequente de recomendaçóes estratégicas por área analisada e a definição de políticas de apoio que suportassem as recomendaçôes formuladas (Proinov, 2002).

Em 2007, começaram a dar-se passos decisivos na criação e dinamização de Polos de Competitividade e/ ou clusters, não só pela configuração de medidas concretas no âmbito do Plano Tecnológico, que previam o mapeamento dos clusters e respetiva grelha de cruzamento com territórios, 
mas também o lançamento de uma fase piloto através do apoio a casos experimentais e a realização de encontros setoriais para divulgação.

Deste modo, o QREN 2007-2013 apresentou-se como um instrumento de integração operacional de prioridades estratégicas relativas ao reforço da cooperação, ao robustecimento da inovação e da investigação e desenvolvimento tecnológico e ao aumento da projeçáo internacional e assumiu-se como o principal alicerce da política de apoio à clusterização. Segundo o relatório final-Estudo de Avaliação da Estratégia e do Processo de Implementação das Estratégias de Eficiência Coletiva- Tipologia Clusters do QREN, os instrumentos de cofinanciamento dos Programas Operacionais Regionais (Norte, Centro, Lisboa, Alentejo e Algarve) e dos Programas Operacionais temáticos (Fatores de Competitividade, Potencial Humano e Valorização do Território) foram identificados como importantes mobilizadores das dinâmicas de eficiência coletiva. No sentido da estruturação de uma política que se desejava articulada e sistémica, previu-se que o apoio à clusterização beneficiaria também do Programa de Desenvolvimento Rural (Proder) e do Programa Operacional Pesca (Promar).

O contributo dos diferentes programas e instrumentos de apoio para os processos de clusterização foi formalizado no enquadramento das Estratégias de Eficiência Coletiva (EEC). Este documento foi o primeiro passo no sentido da operacionalização da política por via da identificação de mecanismos de seletividade (por exemplo, orçamentos específicos e majoraçôes), que permitiriam a discriminação positiva de iniciativas com reconhecido interesse para a consolidação de EEC. Muitos destes mecanismos surgiam, neste documento, associados a instrumentos do COMPETE, destacando-se os Sistemas de Incentivos às Empresas do QREN e o Sistema de Apoio às Açóes Coletivas (SIAC).

O Enquadramento das Estratégias de Eficiência Coletiva através dos processos de clusterizaçâo poderiam estar suportados em Polos ou Clusters e tornou necessário o reconhecimento formal das EEC a apoiar. Além disso, incluiu também, um conjunto de condiçôes necessárias ao reconhecimento dos Polos e dos Clusters, a existência de uma parceria que integrasse atores relevantes para a consolidação das estratégias (nomeadamente empresas e instituições de suporte - instituiçôes de investigação e desenvolvimento tecnológico e de assistência tecnológica, instituiçóes de ensino superior e formação profissional, associações empresariais, entidades regionais, etc.), prevendo-se que esta parceria fosse liderada por uma associação desejavelmente constituída para o efeito (Entidade Gestora). $\mathrm{Na}$ sequência do processo de reconhecimento foram, em julho de 2009, reconhecidas formalmente 19 EEC: 11 Pólos e 8 Clusters (tabela 2). 


\section{Tabela 2}

\section{Pólos e clusters reconhecidos em Portugal pelo programa COMPETE}

\begin{tabular}{|c|c|}
\hline Designação & Entidade Gestora \\
\hline Pólo de Competitividade da Saúde & $\begin{array}{l}\text { Health Cluster Portugal - Associação do Pólo de } \\
\text { Competitividade da Saúde }\end{array}$ \\
\hline Pólo de Competitividade da Moda & Associação Pólo de Competitividade da Moda \\
\hline $\begin{array}{l}\text { Pólo de Competitividade e Tecnologia } \\
\text { Agroindustrial }\end{array}$ & $\begin{array}{l}\text { Associaçáo Integralar - Intervençáo de Excelência } \\
\text { no Setor Agroalimentar }\end{array}$ \\
\hline $\begin{array}{l}\text { Pólo de Competitividade e Tecnologia } \\
\text { da Energia }\end{array}$ & $\begin{array}{l}\text { Associaçáo PCTE - Pólo de Competitividade e } \\
\text { Tecnologia da Energia }\end{array}$ \\
\hline $\begin{array}{l}\text { Pólo de Competitividade e Tecnologia } \\
\text { das Indústrias de Base Florestal }\end{array}$ & $\begin{array}{l}\text { Associaçáo para a Competitividade da Indústria } \\
\text { da Fileira Florestal }\end{array}$ \\
\hline $\begin{array}{l}\text { Pólo de Competitividade e Tecnologia } \\
\text { Engineering \& Tooling }\end{array}$ & $\begin{array}{l}\text { Associaçáo-POOL-NET - Portuguese Tooling } \\
\text { Network }\end{array}$ \\
\hline $\begin{array}{l}\text { Pólo de Competitividade e Tecnologia } \\
\text { das Indústrias de Refinação, Petroquí- } \\
\text { mica e Química Industrial }\end{array}$ & $\begin{array}{l}\text { Associação das Indústrias da Petroquímica, Quí- } \\
\text { mica e Refinaçáo }\end{array}$ \\
\hline $\begin{array}{l}\text { Pólo de Competitividade e Tecnologia } \\
\text { das Indústrias da Mobilidade }\end{array}$ & $\begin{array}{l}\text { CEIIA - Centro para a Excelência e Inovação na } \\
\text { Indústria Automóvel }\end{array}$ \\
\hline $\begin{array}{l}\text { Pólo de Competitividade das Tecnolo- } \\
\text { gias de Produçáo - PRODUTECH }\end{array}$ & $\begin{array}{l}\text { PRODUTECH - Associação para as Tecnologias } \\
\text { de Produção Sustentável }\end{array}$ \\
\hline $\begin{array}{l}\text { Pólo das Tecnologias de Informação, } \\
\text { Comunicaçáo e Eletrónica - TICE.PT }\end{array}$ & $\begin{array}{l}\text { Associação TICE.PT - Associação para o Polo de } \\
\text { Tecnologias de Informaçãa, Comunicação e } \\
\text { Eletrónica }\end{array}$ \\
\hline $\begin{array}{l}\text { Pólo de Competitividade e Tecnologia } \\
\text { do Turismo }\end{array}$ & Estrutura de Projeto "Turismo 2015“ \\
\hline $\begin{array}{l}\text { Cluster das Empresas de Mobiliário de } \\
\text { Portugal }\end{array}$ & $\begin{array}{l}\text { Associação para o Pólo de Excelência e Inovaçáo } \\
\text { das Empresas de Mobiliário de Portugal }\end{array}$ \\
\hline Cluster Agroindustrial do Centro & $\begin{array}{l}\text { InovCluster - Associaçáo do Cluster Agroindus- } \\
\text { trial do Centro }\end{array}$ \\
\hline $\begin{array}{l}\text { Cluster das Indústrias Criativas na } \\
\text { Região do Norte }\end{array}$ & $\begin{array}{l}\text { ADDICT - Agência para o Desenvolvimento das } \\
\text { Indústrias Criativas }\end{array}$ \\
\hline Cluster Habitat Sustentável & $\begin{array}{l}\text { Associação Plataforma para a Construção Susten- } \\
\text { tável }\end{array}$ \\
\hline $\begin{array}{l}\text { Cluster do Conhecimento e da Econo- } \\
\text { mia do Mar }\end{array}$ & $\begin{array}{l}\text { Oceano XXI - Associação para o Conhecimento } \\
\text { e Economia do Mar }\end{array}$ \\
\hline Cluster da Pedra Natural & Associação Valor Pedra \\
\hline Cluster Agroindustrial do Ribatejo & $\begin{array}{l}\text { Animaforum - Associaçáo para o Desenvolvi- } \\
\text { mento da Agroindústria }\end{array}$ \\
\hline $\begin{array}{l}\text { Cluster Vinhos da Região Demarcada } \\
\text { do Douro }\end{array}$ & $\begin{array}{l}\text { ADVID - Associaçáo para o Desenvolvimento da } \\
\text { Viticultura Duriense }\end{array}$ \\
\hline
\end{tabular}

Fonte: elaboração própria com base na informação do QREN (2007-2013). 
As Entidades Gestoras representam um ecossistema complexo e constituem-se como importantes dinamizadoras e beneficiárias do sistema de clusterização nacional. Para além destas, também beneficiam das políticas de clusterização outras entidades, nomeadamente as empresas e instituiçôes de suporte associadas ou não, com ou sem projetos âncora/projetos complementares relevantes para a concretização da estratégia definida para os diferentes setores e integrada num Programa de Ação.

\section{Proposta metodológica para identificaçáo de clusters}

\subsection{A identificaçâo de clusters: algumas metodologias}

A constante utilização do conceito cluster em diferentes contextos levou, muitas vezes ao seu uso inadequado (Martin e Sunley, 2003). A elasticidade do conceito de cluster é exemplificativa de uma ausência de metodologias concretas para a identificação de clusters. Esta falta de rigor e a flexibilidade na aplicação de critérios avulsos originam uma sobre identificação de clusters ao nível de indústrias tradicionalmente mais analisadas (Engelstof et al., 2006).

Engelstof et al. (2006) analisaram as diversas formas usadas na identificação de clusters tendo concluído que o elevado número de clusters identificados resulta de uma análise exígua face à inconsistência metodológica que caracteriza tais estudos. Já Malmberg e Maskell (1997) sublinham o facto da maioria dos estudos que se propóem identificar clusters, assentam na análise simples da concentração geográfica das indústrias, ignorando por completo que o conceito de cluster contém, também, na sua essência a noção de interligação entre os agentes. É de referir que são poucos os estudos encontrados cujo objetivo fosse validar a existência de clusters. Tal tende a derivar, em grande parte, da dificuldade em definir logo à partida o conceito - agravado, pela elevada heterogeneidade das atividades que cada setor inclui. Hofe e Chen (2006) explicam que a ausência de uma metodologia científica clara e rigorosa, para identificar e distinguir clusters de uma simples concentração geográfica de agentes, leva à utilização abusiva da terminologia de cluster.

Apesar da pouca atenção que as questóes metodológicas têm tido no âmbito da temática dos clusters, alguns estudos abordam a questão de uma forma mais ou menos direta tendo como exemplo McRae-Williams (2004) que apresenta uma metodologia de identificação de clusters que deve combinar informação quantitativa e qualitativa. Assim uma análise que pretenda identificar e validar a existência de clusters desenvolve-se a partir de dois pontos de partida possíveis. Por um lado, seguir um estudo de 
caso em que se suspeite à priori da existência do cluster, neste caso, o estudo pretende validar e identificar se se trata mesmo de um cluster ou não. Alternativamente, as análises podem partir de uma perspetiva mais geral, não havendo suspeitas prévias da existência de clusters, o objetivo não é apenas validar mas sim identificar clusters. Nesta segunda abordagem, Braunerhjelm e Carlsson, (1999) afirmam que o que se tenta fazer é identificar polos de concentraçáo geográfica elevada de determinadas indústrias ou atividades e depois validar cada um, usando medidas da interação entre os agentes locais.

Não obstante estas abordagens a maioria dos estudos que procuram identificar clusters seguem uma abordagem de estudo de caso e frequentemente carecem de rigor, não sendo os clusters identificados, quantitativamente validados (Engelstof et al., 2006). Se por um lado, o estudo de caso permite mais facilmente complementar a análise quantitativa com dados de natureza qualitativa, por outro lado, a generalização dos resultados torna-se mais difícil. Assim sendo é fundamental definir uma metodologia para implementar a identificação de clusters. E um aspeto essencial a ter em conta em qualquer metodologia proposta para a identificação de clusters é verificar quer a aglomeração quer a interação (Natário et al., 2011). No entanto, a maior parte dos estudos neste âmbito negligencia a interação entre agentes, focando quase exclusivamente o aspeto da concentração geográfica (Hofe e Chen, 2006).

O objetivo deste estudo consiste em analisar os oito clusters Portugueses reconhecidos pelo COMPETE no âmbito QREN, para o período 2007-13 e verificar se prefiguram, funcionam e têm as características necessárias para a classificação de cluster. Para o efeito, e no sentido de colmatar algumas das críticas anteriormente discutidas, efetua-se o estudo de indicadores que constituem medidas de concentração geográfica, bem como, da aplicação de um inquérito por Questionário para analisar as interaçóes dentro do cluster.

Face ao exposto de seguida serão apresentadas as principais as medidas de concentração utilizadas neste estudo, nomeadamente o quociente de localização, o índice Hirschman-Herfindahl modificado, o índice de participaçáo relativa e o coeficiente de especializaçáo tabela 3.

Segundo Pinheiro et al. (2008), Carvalho (2009) e Pereira (2009) o Quociente de Localização (QL) tem um papel central na identificação de clusters. $\mathrm{O}$ numerador QL mede a concentração relativa da variável no setor j na regiâo (centro, norte e sul dependendo do cluster em análise) enquanto o denominador mede a concentraçáo relativa da variável, do mesmo setor, mas em relação a Portugal. Este indicador, apresenta limitaçóes uma vez que não está definido o quanto acima da média será 


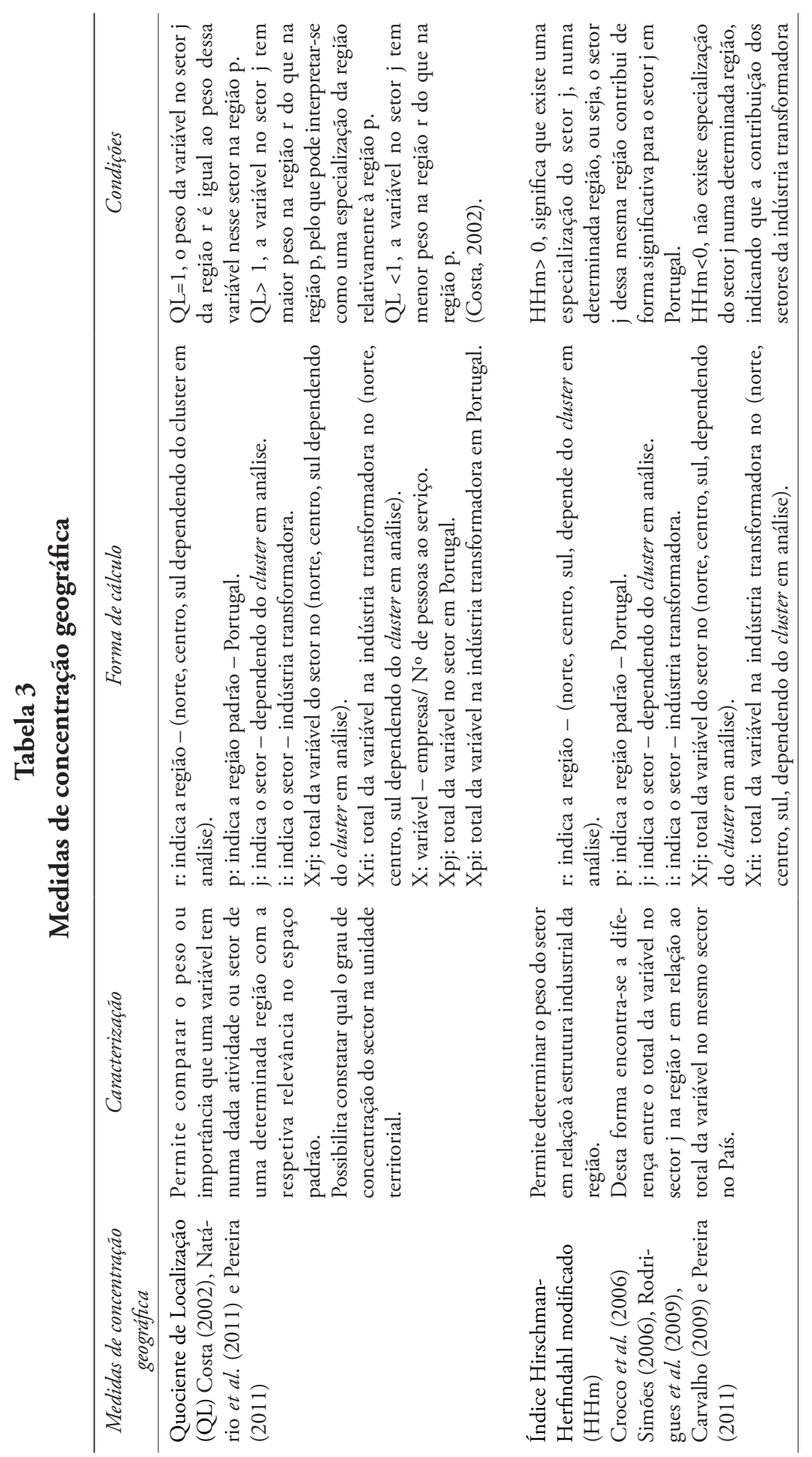




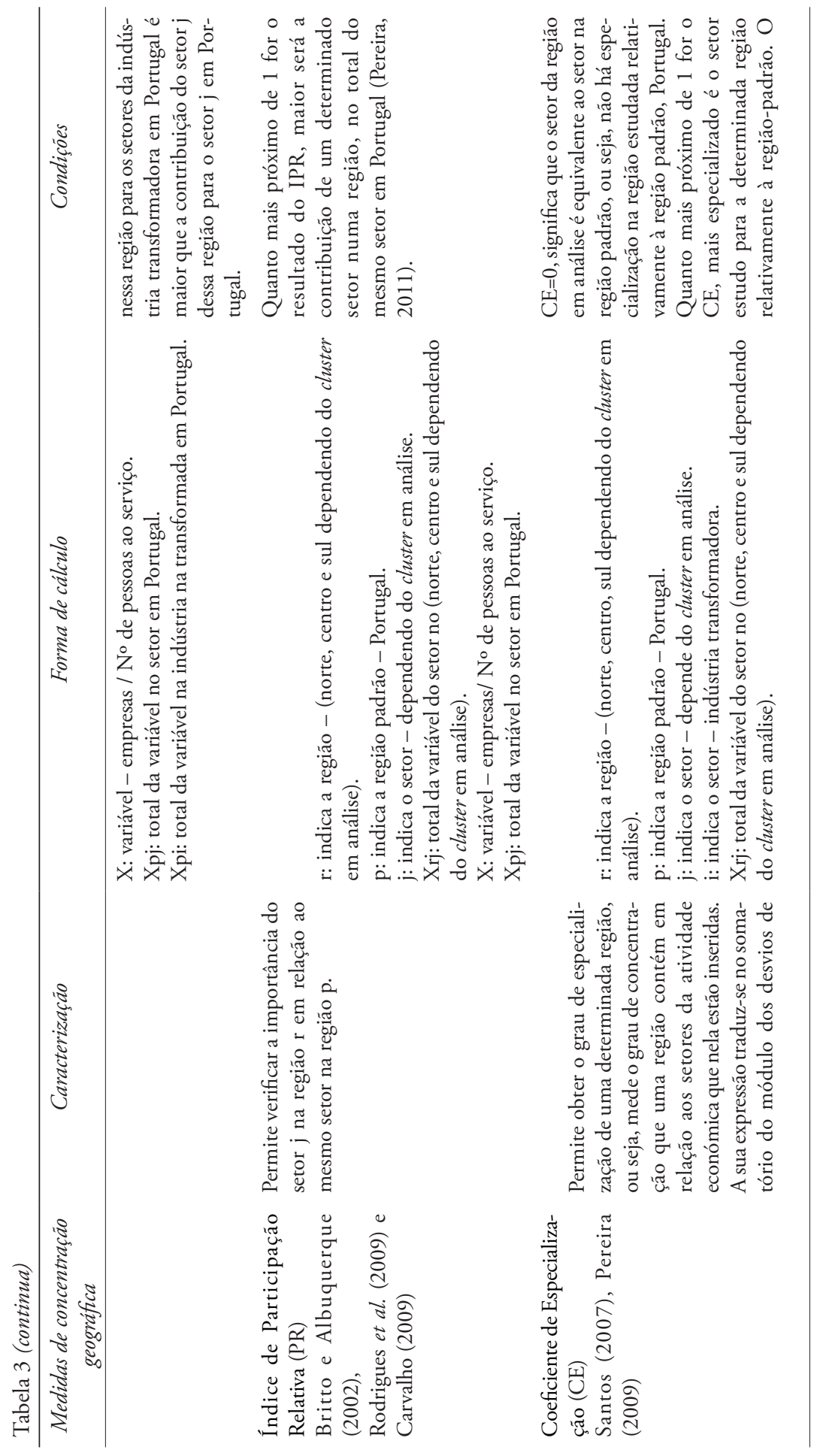




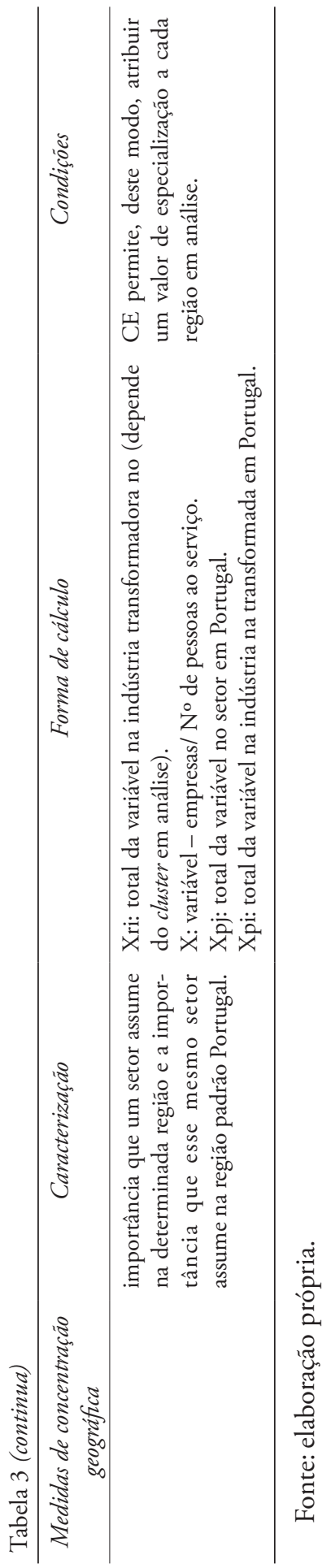


considerável o quociente assumir para que se identifique a presença de um possível cluster.

Held (1996) usa o valor teórico de referência 1, já Bergman e Feser (1999) defendem que um cluster deve apresentar um nível de aglomeração/ especialização relativo superior a $25 \%$ da média. Ou seja, para estes últimos autores deve-se usar 1.25 como o valor de referência. Por sua vez, Braunerhjelm e Carlsson (1999), no seu estudo de identificação de clusters no Ohio e na Suécia, usam 1.30 como o valor mínimo de especialização a partir do qual, se poderá falar da existência latente de um cluster.

Já Sölvell et al. (2008), consideram que o valor de referência é 2.00 . Ainda mais exigente no seu critério, surge Isaksen (1996) que determina que o nível de aglomeração só é significativo quando o quociente de localizaçáo for superior a 3.00. Discordando dos autores anteriores aparece o contributo de Kumral e Deger (2006) que apresentam uma alternativa no sentido de distinguir entre diferentes níveis de concentração, usando dois valores de referência: 1.25 como o nível mínimo para se considerar a aglomeração significativa e 5.00 como a referência a partir do qual essa aglomeração é muito elevada em determinada indústria e regiáo (quadro 1).

\section{Quadro 1}

Diversidade do valor de referência no quociente de localizaçáo

\begin{tabular}{|c|c|c|}
\hline Indicador & $\begin{array}{l}\text { Valor de referência } \\
\text { (threshold) }\end{array}$ & Estudos \\
\hline \multirow{6}{*}{ Quociente de localização } & 1.00 & Held (1996) \\
\hline & 1.25 & $\begin{array}{l}\text { Bergman e Feser (1999); Miller et } \\
\text { al. (2001) }\end{array}$ \\
\hline & 1.30 & Braunerhjelm e Carlsson (1999) \\
\hline & 2.00 & Sölvell et al. (2008) \\
\hline & 3.00 & Isaksen (1996) \\
\hline & 1.25 e 5.00 & Kumral e Deger (2006) \\
\hline
\end{tabular}

Fonte: elaboração própria.

Existem ainda outros indicadores que poderiam ser utilizados: a análise Shift-Share e a análise input-output. Todavia, não se apresentam uma vez que não vão ser utilizados neste estudo.

\subsection{Técnica de investigaçáo: questionário}

Dentro das mais variadas técnicas de recolha de dados, neste estudo, é utilizado o inquérito por questionário, para avaliar a interação entre os 
agentes. A primeira questão incide sobre a avaliação da densidade de rede das instituiçôes de apoio ao desenvolvimento do cluster, as respostas são de escolha múltipla, numa escala de Likert de 0 a 3 desde 0 -inexistente,1-fraca, 2-média e 3-forte. A segunda questão permite avaliar as ligaçôes do cluster com as diversas atividades, numa escala de Likert de 1 a 5 sendo que o 1 corresponde a discordo totalmente e o 5 corresponde a concordo totalmente. $\mathrm{Na}$ terceira e última questão pretende-se avaliar as relações de cooperação e interação dos clusters com uma diversificada rede de instituiçóes, numa escala de Likert de 0 a 3, sendo 0 -inexistente, 1-fraca, 2-média e 3-forte. O questionário em questáo foi enviado, em fevereiro de 2014, por email, para o endereço de email disponibilizado no site de cada cluster, aos oito clusters reconhecidos pelo COMPETE e apenas se obtiveram cinco respostas.

\section{Análise de resultados}

\subsection{Análise dos indicadores de concentração e especializaçáo}

As variáveis utilizadas no calculo dos indicadores de concentração geográfica foram, por um lado, o número de empresas no setor em análise e, por outro, o número de pessoas ao serviço nos diferentes setores, localizadas na Nomenclatura das Unidades Territoriais para fins Estatísticos (NUTS) e de acordo com a Classificação das Atividades Económicas Revisão 3 (CAE Rev.3), tendo como padrão de referência Portugal e as respetivas regióes onde é verificada uma concentração das indústrias em estudo, região norte e região centro, conforme a sede do cluster em análise. Para investigar se os clusters reconhecidos atuam como clusters optou-se por utilizar o Quociente de Localização, o Índice Hirschman-Herfindahl modificado, o Índice de Participação Relativa e o Coeficiente de Especialização. Neste estudo utilizou-se a região Centro ou Norte consoante o cluster em estudo, considerando então as variáveis número de empresas; emprego; e número de pessoas ao serviço, para o ano de 2012.

De forma a garantir o sigilo e anonimato das respostas dos clusters, estes serão classificados como, Clusters A, Cluster B, Cluster C, Cluster D e Cluster E. De seguida, apresenta-se a análise aos indicadores referidos, para três dos cinco clusters para os quais se obteve resposta (quadro 2). A ausência de cálculos para o cluster $\mathrm{D}$ e E deve-se ao facto de náo se conseguir especificar e singularizar a região à qual está afeto o setor.

Cluster A: No quadro 2 apresentam-se os resultados obtidos do cálculo dos diversos indicadores para o setor do cluster A para o ano de 2012, 
sediado na região Norte. Como é visível o Quociente de Localização é muito superior a 1 (tanto na variável emprego como na variável número de empresas) para o setor em observação, o que significa que o emprego e o número de empresas no setor tem um maior peso na regiáo Norte do que em Portugal. Podemos concluir que estes valores estão de acordo com quatro dos seis estudos, sendo eles o de Held (1996) que defende que o valor de referência tem de ser superior a 1.00, os de Bergman e Feser (1999); Miller et al. (2001), que defendem que valor de referência tem de ser superior a 1.25, o de Braunerhjelm e Carlsson (1999) que defendem o valor de referência tem de ser superior a 1.30 e, por último, o de Kumral e Deger (2006) que defendem que o valor de referência náo deve ser inferior a 1.25 e que 5.00 é a referência a partir da qual a aglomeração é considerada muito elevada.

Relativamente aos resultados obtidos do índice de Hirschman-Herfindahl modificado $(\mathrm{HHm})$ ambas as variáveis estudadas apresentam valores superiores a 0 no ano em análise, o que significa que existe uma especialização do setor em estudo na regiáo Norte.

\section{Quadro 2}

\section{Indicadores de concentraçáo para o cluster A, B e C}

\begin{tabular}{|c|c|c|c|c|}
\hline Indicadores & Variável & Cluster A & Cluster B & Cluster $C$ \\
\hline \multirow{2}{*}{$\begin{array}{l}\text { Quociente de } \\
\text { Localizaçáao } \\
\text { (QL) }\end{array}$} & No empresas & 1.91 & 1.46 & 0.79 \\
\hline & $\begin{array}{c}\text { No de pessoal ao } \\
\text { serviço }\end{array}$ & 1.93 & 1.58 & 0.66 \\
\hline \multirow{2}{*}{$\begin{array}{l}\text { Índice de Hirs- } \\
\text { chman-Herfin- } \\
\text { dahl modificado } \\
(\text { HHm })\end{array}$} & No empresas & 0.15 & 0.07 & $(0.07)$ \\
\hline & $\begin{array}{c}\text { No de pessoal ao } \\
\text { serviço }\end{array}$ & 0.19 & 0.04 & $(0.11)$ \\
\hline \multirow{2}{*}{$\begin{array}{l}\text { Índice de } \\
\text { participaçáo } \\
\text { relativa } \\
\text { (PR) }\end{array}$} & No empresas & 0.62 & 0.32 & 0.26 \\
\hline & $\begin{array}{c}\text { No de pessoal ao } \\
\text { serviço }\end{array}$ & 0.64 & 0.29 & 0.22 \\
\hline \multirow{2}{*}{$\begin{array}{c}\text { Coeficiente de } \\
\text { especializaçáo } \\
\text { (CE) }\end{array}$} & No empresas & 0.002 & 0.002 & $(0.005)$ \\
\hline & $\begin{array}{c}\text { No de pessoal ao } \\
\text { serviço }\end{array}$ & 0.004 & 0.007 & $(0.005)$ \\
\hline
\end{tabular}

Fonte: elaboração própria a partir dos dados do Instituto Nacional de Estatística (INE, 2015).

O Índice de Participação Relativa indica a contribuição do setor em observação na região Norte, quando comparado com Portugal. Através do quadro 2 observa-se que o setor tem valores próximos de 1 , variando 0.62 na variável empresas e 0.64 na variável pessoal ao serviço o que significa que as suas contribuiçóes na região Norte são evidentes. 
Por sua vez, os resultados obtidos do cálculo do Coeficiente de Especialização exibem, maioritariamente valores muito próximos do 0 , o que representa que não há especialização do setor da regiấo norte comparativamente a Portugal.

Cluster B: O quadro 2 sintetiza os principais indicadores de concentração geográfica para o setor do cluster $\mathrm{B}$ sediado na região Centro. Da análise ao quadro 2 é visível, no período em análise, que o QL é superior a 1 (em ambas as variáveis) para o setor em observação, o que significa que o emprego e o $\mathrm{n}^{\circ}$ de empresas no setor tem um maior peso na regiáo Centro do que em Portugal. Sendo que, relativamente aos diversos estudos dos valores de referência para este indicador, estes mesmos resultados também estão de acordo com quatro dos seis estudos, nomeadamente com o de Held (1996) que defende que o valor de referência tem de ser superior a 1.00, com os de Bergman e Feser (1999); Miller et al. (2001), que defendem que valor de referência tem de ser superior a 1.25 , com o de Braunerhjelm e Carlsson (1999) que defendem o valor de referência tem de ser superior a 1.30 e, por último, com o de Kumral e Deger (2006) que defendem que o valor de referência não deve ser inferior a 1.25 e que 5.00 é a referência a partir da qual a aglomeração é considerada muito elevada.

Relativamente aos resultados obtidos do índice $\mathrm{HHm}$, quer em termos da variável emprego quer do número de empresas, verifica-se que os valores são superiores a 0 no ano em análise, o que significa que existe uma especialização do setor em estudo na regiáo Centro.

No que respeita ao índice de PR é possível verificar que o setor tem valores superiores a 0 , o que significa que as suas contribuiçóes na região centro são notórias, mas não são representativas porque os valores não são próximos de 1, estando abaixo dos 0.5 .

$\mathrm{O}$ último valor calculado foi o $\mathrm{CE}$ que exibe, maioritariamente valores muito próximos do 0 , levando à conclusão que não há especialização do setor da regiāo Centro comparativamente a Portugal.

Cluster C: Da análise aos resultados obtidos para os diferentes indicadores de concentração para o setor do cluster $C$ na regiáo Norte, para o ano de 2012 conclui-se que o QL é inferior a 1 (tanto no emprego como no $n^{\circ}$ de empresas) para o setor em observação, o que significa que o emprego e o ${ }^{\circ}$ de empresas no setor em estudo têm um peso maior em Portugal do que na regiáo Norte. Sendo que relativamente aos diversos estudos dos valores de referência para este indicador, estes mesmos resultados não estão de acordo com nenhum dos autores mencionados no quadro 1 . 
Os resultados obtidos para o índice $\mathrm{HHm}$ são inferiores a 0 , o que significa que não existe uma especialização do setor em estudo na região Norte (quadro 2). O índice de PR indica a contribuição do setor em observação na regiáo Norte, quando comparado com Portugal. Observa-se ainda que que o setor tem valores superiores a 0 mas inferiores a 1 , variando entre os 0.26 nas empresas e 0.23 no pessoal ao serviço o que significa que as suas contribuiçôes na região Norte são pouco significativas. Os resultados obtidos do cálculo da CE exibem, valores negativos, inferiores a 0 , o que mostra que não há especialização do setor na região Norte comparativamente a Portugal.

\subsection{Análise dos resultados dos questionários}

Para inferir sobre a presença e funcionamento do cluster é importante além da concentração geográfica, contemplar a intensidade de redes de interação e cooperação. Para o efeito optou-se pela utilização de um questionário composto por três questôes: 1 . Avaliação da densidade da rede de instituiçóes de apoio ao desenvolvimento dos clusters; 2 . Avaliação das ligaçóes dentro dos clusters; 3. Avaliação das relaçôes de cooperação e interação dos clusters.

Os clusters reconhecidos que serão objeto de análise são cinco: Cluster A, Cluster B, Cluster C, Cluster D e Cluster E, pois apenas obtivemos respostas ao questionário, por parte dos responsáveis destes clusters. De seguida apresentam-se a análise e interpretação das respostas obtidas. (quadros 3, 4 e 5).

\section{Quadro 3}

Avaliaçáo da densidade da rede de instituiçóes de apoio ao desenvolvimento dos clusters A, B, C, D e E

\begin{tabular}{|c|c|c|c|c|c|}
\hline $\begin{array}{l}\text { Instituiçóes de apoio ao desenvolvi- } \\
\text { mento do cluster: }\end{array}$ & $\begin{array}{c}\text { Cluster } \\
\text { A }\end{array}$ & $\begin{array}{c}\text { Cluster } \\
B\end{array}$ & $\begin{array}{c}\text { Cluster } \\
\text { C }\end{array}$ & $\begin{array}{c}\text { Cluster } \\
\text { D }\end{array}$ & $\begin{array}{l}\text { Cluster } \\
\text { E }\end{array}$ \\
\hline Instituições de ensino superior & Média & Forte & Forte & Forte & Média \\
\hline $\begin{array}{l}\text { Centros de investigação e tecno- } \\
\text { lógicos }\end{array}$ & Fraca & Forte & Média & Forte & Média \\
\hline Centros de formação & Fraca & Média & Fraca & Média & \\
\hline Associaçôes empresariais/comerciais & Média & Forte & Média & Forte & Média \\
\hline $\begin{array}{l}\text { Centros de certificaçáo de quali- } \\
\text { dade }\end{array}$ & Fraca & Média & $\begin{array}{l}\text { Inexis- } \\
\text { tente }\end{array}$ & Forte & Média \\
\hline Autarquias locais & Média & Média & Média & Média & Média \\
\hline
\end{tabular}

Fonte: elaboração própria. 


\section{Quadro 4 \\ Avaliação das ligaçóes dentro dos clusters: clusters A, B, C, D e E}

\begin{tabular}{|c|c|c|c|c|c|}
\hline & $\begin{array}{c}\text { Cluster } \\
\text { A }\end{array}$ & $\begin{array}{c}\text { Cluster } \\
B\end{array}$ & $\begin{array}{c}\text { Cluster } \\
\text { C }\end{array}$ & $\begin{array}{c}\text { Cluster } \\
\text { D }\end{array}$ & $\begin{array}{c}\text { Cluster } \\
\text { E }\end{array}$ \\
\hline $\begin{array}{l}\text { As atividades estão fortemente liga- } \\
\text { das por relaçóes diretas ou indiretas } \\
\text { de fornecimento (bens e serviços } \\
\text { intermédios, componentes e subsis- } \\
\text { temas, bens de equipamento e sof- } \\
\text { tware especializado, serviços de apoio } \\
\text { e serviços de investigaçáo aplicada } \\
\text { contratualizada). }\end{array}$ & 4 & 3 & 3 & 5 & \\
\hline $\begin{array}{l}\text { As atividades estão fortemente liga- } \\
\text { das por relaçóes diretas ou indiretas } \\
\text { na exploraçáo de tecnologias simila- } \\
\text { res para fins distintivos. }\end{array}$ & 3 & 3 & 1 & 5 & 3 \\
\hline $\begin{array}{l}\text { As atividades estão fortemente liga- } \\
\text { das por relaçóes diretas ou indiretas } \\
\text { na exploraçáo de circuitos de distri- } \\
\text { buição comuns e sinergias de marca. }\end{array}$ & 4 & 5 & 2 & 4 & \\
\hline $\begin{array}{l}\text { As atividades estão fortemente liga- } \\
\text { das por relaçóes diretas ou indiretas } \\
\text { no aproveitamento do mesmo tipo } \\
\text { de competências e conhecimentos. }\end{array}$ & 4 & 5 & 3 & 5 & 3 \\
\hline $\begin{array}{l}\text { As relaçóes de concorrência entre as } \\
\text { empresas do cluster são elevadas }\end{array}$ & 5 & 4 & 4 & 4 & \\
\hline $\begin{array}{l}\text { As atividades estão fortemente liga- } \\
\text { das por relaçóes baseadas na confian- } \\
\text { ça e nas alianças estratégicas entre as } \\
\text { empresas. }\end{array}$ & 3 & 5 & 2 & 4 & \\
\hline $\begin{array}{l}\text { Existem fortes relaçôes com os agen- } \\
\text { tes económicos e com o meio envol- } \\
\text { vente. }\end{array}$ & 4 & 4 & 3 & 5 & \\
\hline $\begin{array}{l}\text { A integração do cluster é importante } \\
\text { para o desenvolvimento económico. }\end{array}$ & 5 & 5 & 5 & 5 & 3 \\
\hline
\end{tabular}

Legenda: (1: discordo totalmente... 5: concordo totalmente)

Fonte: elaboração própria. 


\section{Quadro 5}

\section{Avaliaçáo das relaçóes de cooperaçáo e interação do cluster Clusters A, B, C, D e E}

\begin{tabular}{|c|c|c|c|c|c|}
\hline & $\begin{array}{c}\text { Cluster } \\
\text { A }\end{array}$ & $\begin{array}{c}\text { Cluster } \\
B\end{array}$ & $\begin{array}{c}\text { Cluster } \\
\text { C }\end{array}$ & $\begin{array}{c}\text { Cluster } \\
D\end{array}$ & $\begin{array}{c}\text { Cluster } \\
\text { E }\end{array}$ \\
\hline Fornecedores & Média & Forte & Média & Forte & Fraca \\
\hline Empresas concorrentes & Média & NA & Média & Média & \\
\hline Clientes & Média & Forte & Média & Forte & Média \\
\hline Instituições ensino superior & Média & Forte & Média & Forte & Média \\
\hline $\begin{array}{l}\text { Centros de investigaçáo e tecno- } \\
\text { lógicos }\end{array}$ & Média & Forte & Média & Forte & \\
\hline Centros de formação & Média & Forte & Fraca & Média & \\
\hline $\begin{array}{l}\text { Associaçōes empresariais/comer- } \\
\text { ciais }\end{array}$ & Média & Média & Fraca & Forte & Média \\
\hline $\begin{array}{l}\text { Centros de certificação de quali- } \\
\text { dade }\end{array}$ & Média & Média & Fraca & Forte & \\
\hline Autarquias locais & Média & Forte & Fraca & Média & Média \\
\hline Consultores & Média & Fraca & Média & Forte & \\
\hline
\end{tabular}

Fonte: elaboração própria.

Cluster A: O sucesso de um cluster está diretamente relacionado com a existência de uma rede densa de Instituiçóes de apoio ao seu funcionamento/desenvolvimento. Neste caso, no cluster A existe uma densidade média/baixa de instituiçóes de apoio ao seu desenvolvimento, com realce para uma densidade média nomeadamente de instituições de ensino superior, autarquias locais, associações empresariais/comerciais e fraca ao nível de centros de investigação e tecnológicos, centros de formação e de centros de certificação da qualidade.

$\mathrm{Na}$ segunda questão, relacionada com a avaliação das ligações do cluster pode afirmar-se que, no geral, no cluster A se verificam relaçóes de concorrência entre as empresas do cluster elevadas e que a integração do cluster é importante para o desenvolvimento económico. Por sua vez, também se verifica, com um nível de concordância 4, que as atividades estão fortemente ligadas por relaçôes diretas ou indiretas de fornecimento, na exploração de circuitos de distribuição comuns e sinergias de marca e no aproveitamento do mesmo tipo de competências e conhecimentos e por fim que existem fortes relaçôes com os agentes económicos e com o meio envolvente. Quanto às atividades estarem fortemente ligadas por relaçôes diretas ou indiretas na exploração de tecnologias similares para fins distintivos e serem baseadas na confiança e nas alianças estratégicas entre as empresas, estas são menos valorizadas pelo cluster A. 
$\mathrm{Na}$ terceira e última questão verifica-se que existem relaçóes de cooperação e interação das empresas do cluster A com os diferentes atores sejam eles fornecedores, clientes, empresas concorrentes, ou instituiçóes de ensino superior, centros de formação entre outros. Essas relaçóes são avaliadas como médias.

Face a estes resultados, pode concluir-se que de forma geral o cluster $A$ funciona e atua de acordo com as características para a classificação como cluster, principalmente no que diz respeito à intensidade de redes de interação e cooperação.

Cluster B: Relativamente à primeira questão, pode constatar-se que, de uma forma geral, existe uma forte densidade da rede de instituiçóes de apoio ao desenvolvimento do cluster $\mathrm{B}$, nomeadamente em termos de instituiçóes de ensino superior, centros de investigação tecnológico e associações empresariais/comerciais e uma densidade média ao nível dos centros de formação, dos centros de certificação de qualidade e das autarquias locais.

Na segunda questão, pode afirmar-se que de um modo geral o cluster B atribui o nível 5, numa escala de 1 a 5 (5-total concordância) ou seja, que as atividades estão fortemente ligadas por relaçóes diretas ou indiretas na exploração de circuitos de distribuição comuns e sinergias de marca, no aproveitamento do mesmo tipo de competências e conhecimentos, que as atividades estão fortemente ligadas por relaçóes baseadas na confiança e nas alianças estratégicas entre as empresas e, por último, que a integração do cluster é importante para o desenvolvimento económico. Além disso, este cluster também se caracteriza por ter relaçóes de concorrência entre as empresas do cluster elevadas e por fortes relaçóes dos agentes económicos com o meio envolvente (valorizadas a um nível 4 na escala de 1 a 5).

Menos valorizadas são as atividades ligadas, por relaçóes diretas ou indiretas, na exploração de tecnologias similares para fins distintivos e de fornecimento (de bens e serviços intermédios, componentes e subsistemas, bens de equipamento e software especializado, serviços de apoio e serviços de investigação aplicada contratualizada).

$\mathrm{Na}$ última questão, sobre a avaliação das relaçóes de cooperação e interação do cluster verifica-se que em geral as relaçóes de cooperação e interação das empresas do cluster B com os diversos atores (fornecedores, clientes, instituiçóes de ensino superior, centros de investigação e tecnológicos, centros de formação e autarquias locais, associações e centros de certificação) oscilam entre forte e médias, exceto com consultores que são consideradas fracas e com empresas concorrentes que são referidas como não aplicável. 
De uma forma geral, dos resultados obtidos conclui-se que o cluster B funciona e atua de acordo com as características de cluster ao nível da densidade da rede e da interação, uma vez que valoriza mais diversas atividades que lhe foram apresentadas e as relaçóes de cooperação e interação do cluster com outras instituiçôes.

Cluster C: No cluster C, de uma forma geral, verifica-se que existe um nível de densidade média da rede de instituiçóes de apoio ao seu funcionamento/desenvolvimento do cluster, particularmente em termos de centros de investigação e tecnológicos, associaçóes empresariais/ comerciais e autarquias locais, e forte em termos de instituiçóes de ensino superior, mas fraca e inexistente, respetivamente, em termos de centros de certificação de qualidade e de centros de formação.

$\mathrm{Na}$ segunda questão relativa às ligaçóes existentes dentro do cluster, embora o cluster $\mathrm{C}$ considere a integraçáo do cluster ser importante para o desenvolvimento económico e que as relaçóes de concorrência entre as empresas do cluster serem elevadas, basicamente ou são fracas ou não se verificam atividades fortemente ligadas, por relaçóes diretas ou indiretas, de fornecimento, no aproveitamento do mesmo tipo de competências e conhecimentos, na exploração de circuitos de distribuição comuns e sinergias de marca e na exploraçáo de tecnologias similares para fins distintivos. Além disso, também são baixas ou inexistentes as relaçôes dos agentes económicos com o meio envolvente e as relaçóes baseadas na confiança e nas alianças estratégicas entre as empresas.

$\mathrm{Na}$ questão sobre as relaçóes de cooperação e interação das empresas do cluster, constata-se que o cluster $\mathrm{C}$ mantém relações médias com fornecedores, empresas concorrentes, clientes, instituições de ensino superior, centros de investigação e tecnológico e com os consultores e fracas com as restantes instituições (centros de formação, associaçóes empresariais/ comerciais, centros de certificação de qualidade e autarquias locais).

Em suma, pode concluir-se que no cluster $\mathrm{C}$ as ligaçóes e relaçóes dentro do cluster não são muito valorizadas nem assumem grande importância apesar considerarem a integraçáo do cluster importante para o desenvolvimento económico.

Cluster D: A avaliaçáo que o cluster D faz da densidade da rede de Instituiçóes de apoio ao desenvolvimento deste cluster é da existência de uma rede forte de instituiçôes de ensino superior, centros de investigação e tecnológicos, centros de certificação de qualidade e ao nível de associaçóes empresariais/comerciais e da existência de uma rede média em termos de empresas concorrentes, de centros de formação e de autarquias locais. 
$\mathrm{Na}$ segunda questáo, de forma geral, verifica-se que no cluster $\mathrm{D}$ as atividades estão fortemente ligadas por relaçóes diretas ou indiretas de fornecimento, na exploração de tecnologias similares para fins distintivos, no aproveitamento do mesmo tipo de competências e conhecimentos e que existem fortes relaçóes com os agentes económicos e com o meio envolvente e que a integração do cluster é importante para o desenvolvimento económico. Além disso, também atribuem uma valorização alta (de 4, numa escala de 1 a 5) ao facto de as atividades estarem fortemente ligadas por relaçóes diretas ou indiretas na exploração de circuitos de distribuição comuns e sinergias de marca, as relações de concorrência entre as empresas do cluster serem elevadas e as atividades estarem fortemente ligadas por relações baseadas na confiança e nas alianças estratégicas entre as empresas.

Na terceira e última questão sobre as relações de cooperação e interação das empresas do cluster, verifica-se que no cluster D existem fortes relaçóes de cooperaçáo e interação com fornecedores, empresas concorrentes, clientes, instituiçôes de ensino superior, centros de investigação e tecnológicos, associações empresariais/comercias, centros de certificação de qualidade e consultores e médias com clientes, centros de formação e autarquias locais.

Em suma, pode concluir-se que o cluster $\mathrm{D}$ as ligaçóes e relaçóes dentro do cluster assumem grande importância assim como as ligaçóes de interação e cooperação do cluster com as diversas instituiçóes, funcionando este como verdadeiro cluster, tendo em conta a interação com os diversos agentes.

Cluster E:_Relativamente à questão sobre a avaliação da densidade da rede de instituiçóes de apoio ao desenvolvimento deste cluster, de uma forma geral existe densidade média de clientes, instituições de ensino superior, centros de investigaçáo e tecnológicos, associaçóes empresariais/comerciais e autarquias locais. Não se obteve resposta ao nível de centros de certificação de qualidade e de centros de formação.

$\mathrm{Na}$ segunda questão apenas se obtiverem três respostas, nomeadamente em relação às atividades estarem fortemente ligadas por relaçôes diretas ou indiretas na exploração de tecnologias similares para fins distintivos, no aproveitamento do mesmo tipo de competências e conhecimentos e ao facto de a integração do cluster ser importante para o desenvolvimento económico, sendo estas valorizadas de 3 (numa escala de 1 a 5).

$\mathrm{Na}$ terceira e última questão, no que diz respeito às relaçóes de cooperação e interação das empresas do cluster, estas são fracas com fornecedores e são médias com clientes, com instituiçôes de ensino superior, associaçóes empresariais/comerciais e com autarquias locais. Não se obteve 
resposta para as relações de cooperação e interação das empresas do cluster $\mathrm{E}$ com as empresas concorrentes, com os centros de investigação e tecnológicos, com os centros de formação e com os consultores.

Em suma, dos resultados interpreta-se que as ligaçôes e as relaçóes dentro do cluster $\mathrm{D}$ não assumem grande importância apesar de a integraçáo do cluster ser importante para o desenvolvimento económico e também assumem relevância média as relaçóes de interação e cooperação, concluindo-se que não está a funcionar na sua plenitude enquanto cluster.

\section{Conclusóes}

O papel dos clusters enquanto plataformas de inovação aberta e de competitividade é inquestionável, reconhecendo-se a sua importância no acesso e partilha de conhecimento e no estímulo de práticas colaborativas. Decorrentes dos fenómenos de globalização e do rápido crescimento tecnológico, registaram-se alteraçóes da forma de estar e operar dos indivíduos e agentes económicos e sociais e no entendimento dos contextos económicos e sociais, obrigando as empresas a competir face a estratégias globais e envolvendo mercados mundiais .

Neste contexto, o desenvolvimento de clusters, enquanto plataformas de concentraçáo de empresas numa determinada região que operam quer como parceiras em interação quer como concorrentes, assumem um papel fundamental para promover a competitividade.

A importância dos clusters tem estado presente nas políticas e programas de clusterização a nível europeu com o objetivo de contribuir para reforçar a competitividade e a eficiência industrial e para promover a inovaçáo e a transformação económica, atendendo, nomeadamente, à procura de mercado e aos desafios das sociedades. A política da clusterização do COMPETE, no âmbito do QREN, permitiu o reconhecimento de 19 Pólos e 8 Clusters e o seu quadro de medidas criou condiçôes favoráveis para a implementação de estratégias assumidas como prioritárias, sendo clara a intenção de construir um "programa de clusterizaçâo" em conformidade com os princípios da operacionalização e integração inteligente. Considera-se que o sucesso de um País depende do desenvolvimento das suas regióes, pelo que cada regiáo deve potenciar os seus recursos de forma ativa, valorizando os recursos locais incentivando a participação da população e foi esta filosofia que suportou a definição dos clusters pelo COMPETE.

Este estudo consistiu em analisar os oito clusters reconhecidos pelo Programa Operacional Fatores de Competitividade, nomeadamente: o Cluster das Empresas do Mobiliário de Portugal, o Cluster Agro-Industrial do Centro, o Cluster das Indústrias Criativas da Região Norte, o Cluster 
do Habitat Sustentável, o Cluster do Conhecimento da Economia e do Mar, o Cluster da Pedra Natural, o Cluster Agro-Industrial do Ribatejo e, por último, o Cluster Dos Vinhos da Regiāo Demarcada do Douro, através do calculo de indicadores e medidas de concentração geográfica e a um questionário para verificar se os clusters, prefiguravam e funcionavam com as características intrínsecas aos conceitos de cluster.

No sentido de complementar a análise de indicadores de concentração geográfica, para verificar se existia interação entre os agentes do cluster aplicou-se então um questionário com três questôes para avaliar a densidade da rede e apoio das instituiçóes ao desenvolvimento dos clusters, as ligações do cluster com as diversas atividades e por último a relação de cooperação e interação dos clusters com uma diversificada rede de instituiçôes.

Da análise aos resultados dos indicadores de concentração geográfica realizada, pode concluir-se que apenas dois dos clusters (A e B) apresentam valores significativos, para que se possa concluir que ambos atuam como clusters, embora o indicador coeficiente de especialização assuma nestes dois clusters maior concentração em Portugal do que nas respetivas regiôes em estudo (Norte e Centro). Relativamente ao cluster $\mathrm{C}$ os resultados náo permitem concluir que existe concentração geográfica de empresas na regiāo comparativamente à média nacional, e por isso que seja considerado como cluster. Saliente-se, no entanto, que estes resultados podem ter sido influenciados pelo facto de o setor deste cluster $\mathrm{C}$ náo contemplar todos os subsectores, uma vez que o INE não dispóe de dados desagregados para abarcar todos os subsectores do setor em análise, tal qual é definido no COMPETE.

Relativamente à densidade de rede de apoio ao desenvolvimento do cluster, às atividades estarem ou não ligadas por relação direta ou indireta com diversos agentes e à interação/cooperação com diversos agentes, conclui-se também que apenas dois dos clusters (B e D) apresentam resultados significativos para estas questóes.

Conclui-se, desta forma, a partir das análises realizadas, que apenas um dos clusters reconhecidos no âmbito do QREN (o cluster B) está a funcionar na sua plenitude enquanto cluster. Só este cumpre com as duas condiçôes necessárias para a classificação de cluster, ou seja, evidencia valores significantes na análise dos indicadores de concentração geográfica e evidencia ligações significativas de interação/cooperação.

Relativamente aos restantes clusters reconhecidos analisados neste estudo, pode concluir-se que o cluster A apresenta indicadores de concentração suscetíveis de se considerar que possa atuar como cluster, mas no que respeita às ligaçôes de interação/cooperação, as mesmas não são significativas. $\mathrm{O}$ cluster $\mathrm{C}$ não apresenta indicadores de concentração signi- 
ficativos, nem as ligações de interação/cooperação são significativas. Já o cluster D não apresenta indicadores de concentração por não se conseguir especificar qual a região onde ele está concentrado, mas no que compete às ligaçóes de interação/cooperação, este apresenta ligaçóes bastante significativas. Por fim, o cluster E não apresenta indicadores de concentração também pelo fato de não se conseguir especificar a regiáo onde ele está concentrado e as relaçóes de interação/cooperação não são significativas.

Foi interessante constatar que apesar de terem sido reconhecidos como clusters, nem todos estão a prefigurar como tal, pelo que comprometem os resultados a serem alcançados e acabam por colocar em causa os objetivos definidos de reduçáo de assimetrias e de desenvolvimento de competitividade quer dos setores quer das regiôes onde estão inseridos. Deste modo, seria de todo importante reforçar as relaçóes de interação e cooperação entre as empresas e entre outras instituiçôes; intensificar a inovação e a Investigação e Desenvolvimento Tecnológico orientada para a comercialização e exploração de produtos e serviços; apostar na produção de bens transacionáveis e na internacionalização; promover o empreendedorismo; estimular a competitividade e a modernização do tecido empresarial e qualificar os recursos humanos e gerar emprego qualificado.

O sucesso dos Polos e a dinamização dos Clusters são fundamentais para o futuro do país e para a sua recuperação face à crise e para projetar no país uma dinâmica de procura permanente da criaçáo de valor, emprego e riqueza. É fundamental que a sociedade se agarre de forma convicta a este desígnio e faça da criação destas formas de competitividade a verdadeira aposta estratégica coletiva para os próximos anos. Os atores (municípios, universidades, associaçóes empresariais) terão que saber desenvolver um verdadeiro "pacto estratégico" para o futuro do seu território.

A principal limitação neste estudo surgiu pelo fato de não se conseguir especificar para cada cluster, qual a região onde estão concentrados e daí não se conseguir determinar as medidas de concentração para todos os clusters. Outra limitação prende-se com o facto de não se ter realizado entrevistas para avaliar a densidade das redes de relaçóes. Por último, outra limitação surge associada ao cluster $\mathrm{C}$, uma vez que o INE não dispunha de dados que permitissem a desagregação de todos os setores. Por este motivo, os resultados obtidos através dos cálculos do grau de concentração não incluem alguns subsetores incluídos no cluster. Outra limitação do estudo predem-se com a abordagem utilizada, que se concentra apenas nas interaçóes e ignora problemas-chaves da avaliação dos clusters, como é o caso dos processos de inovação.

Como pistas de investigação futuras aponta-se em primeiro lugar que na análise aos clusters se contemple outros fatores qualitativos que mostrem 
as principais características dos clusters, assim como a avaliação dos processos de inovação, primeiro numa perspetiva empresarial e depois o impacto do funcionamento dos clusters nas dinâmicas territoriais de inovação, utilizando as diretrizes do Manual de Oslo (OECD, 2005).

Aponta-se ainda um estudo mais pormenorizada e/ou individualizado do contributo desta politica da União Europeia, em termos de estratégias de eficiência coletiva, para o aumento das exportaçôes e da competitividade do setor e/ou regiáo onde está inserido o cluster. Aponta-se também sobre a possibilidade de indagar sobre a influência que cada cluster reconhecido teve sobre as empresas do setor e sobre o setor a que diz respeito. Aponta-se, ainda, alargar o estudo aos polos reconhecidos também pelo COMPETE, procurando analisar o impacto desta política em termos de competitividade.

\section{Referências}

Akgungor, Sedef (2006), “Geographic concentrations in Turkey's manufacturing industry: identifying regional highpoint clusters", Europe and Planning Studies, XIV (2), Taylor and Francis Group, Londres, Inglaterra, pp.169-197.

Becattini, Giacomo (1979), "Dal settore industriale al distretto industriale: alcune considerazione sull'unita d'indagine dell' economia industrial", Rivista di Economia Industriale, II (1), Franco Angeli Edizioni, Bolonha, Itália, pp. 832.

Becattini, Giacomo (1994), "O Distrito Marshalliano: uma noção socioeconómica”, in Georges Benko y Alain Lipietz (orgs.), As regióes ganhadoras-distritos e redes: os novos paradigmas da geografia económica, Celta, Oeiras, Portugal, pp. 19-32.

Becattini, Giacomo, M. Teresa Costa e Juan Trullén (coords.) (2002), Desarrollo local: teorias y estrategias, Editorial Civitas, Espanha.

Bell, Martin e Michael Albu (1999), "Knowledge systems and technological dynamism in industrial clusters in developing countries", World Development, 27 (9), Elsevier, Michigan, Estados Unidos da America, pp. 1715-1734. 
Bergman, Edward y Edward Feser (1999), Industrial and regional clusters: concept and comparative applications, Web book in regional science, Regional Research Institute, West Virginia University, Virginia, Estados Unidos da America, <http://www.rri.wvu.edu/WebBook/ BergmanFeser/contents.ht>, 25 de novembro de 2015.

Braunerhjelm, Punto y Bo Carlsson (1999), "Industry clusters in Ohio and Sweden, 1975-1995", Small Business Economics, XII (4), Springer International Publishing AG, Cham, Suíça, pp. 279-293.

Britto, Jorge y Eduardo da Mota Albuquerque (2002), "Clusters industriais na economia brasileira: uma análise exploratória a partir de dados da RAIS”, Estudos Econômicos, XXXII (1), Universidade de São Paulo, São Paulo, Brasil, pp. 71-102.

Carvalho, Diogo Sá (2009), "Identificando potenciais Arranjos Produtivos Locais (APLs) no Sul do Rio Grande do Sul: uma proposta metodológica", dissertação de mestrado, Instituto de Ciências Humanas e da Informação, Universidade Federal do Rio Grande, Rio Grande, Brasil.

Christensen, Paul, Nan Mcintyre e Lynn Pikholz (2002), Bridging community and economic development-a strategy for using industry clusters to link neighborhoods to regional economy, Shorebank Enterprise Group, Cleveland, Estados Unidos da America.

Costa, José (2002), Compêndio de Economia Regional, Coleção Associação Portuguesa para o Desenvolvimento Regional, Lisboa, Portugal.

Cotright, Joseph (2006), "Making sense of clusters: regional competitiveness and economic development", discussion paper, Brookings Institution Metropolitan Policy Program, Washington, Estados Unidos da America.

Crocco, Marco Aurélio, Rangel Galinari, Fabiana Santos, Mauro Borges Lemos y Rodrigo Simões (2006), "Metodologias de identificação de aglomeraçôes produtivas locais", Revista Nova Economia, XVI (2), Departamento de Ciências Econômicas da Universidade Federal de Minas Gerais, Belo Horizonte, Brasil, pp. 211-241.

Carlsson, Bo, Staffan Jacobsson, Magnus Holmen e Annika Rickne (2002), "Innovation systems: analytical and methodological 
issues” Research Policy, 31 (2), Elsevier, Amsterdã, Holanda, pp. 233-245.

Carlsson, Bo (1995), Technological systems and economic performance: the case of factory automation, Kluwer Academic Publishers, Dordrecht, Londres.

Edquist, Charles (Ed.) (1997), Systems of innovation: technologies, institutions and organization, Taylor and Francis group, Didcot, Londres.

Engelstof, Sten, Chris Jensen-Butler, Ian Smith e Lars Winther (2006), "Industrial clusters in Denmark: theory and empirical evidence", Regional Science, LXXXV (1), John Wiley and Sons, Nova Jersey, Estados Unidos da America, pp. 73-97.

Enright, Michael (2001), "Regional clusters: what we know and what we should know", paper presented for the Kiel Institute International Workshop on Innovation Clusters and Interregional Competition, 12-13 de novembro, Kiel, Alemanha.

Etzkowitz, Henry (2003), "Research groups as 'quase-firms': the invention of the entrepreneurial university", Research Policy, vol. XXXII, Elsevier, Amsterdã, Holanda, pp. 109-121.

Fernandes, Ana Cristina e João Policarpo Lima (2006), "Cluster de serviços: contribuiçóes conceptuais com base em evidências do Pólo Médico do Recife", Revista Nova Economia, XVI (1), Departamento de Ciências Económicas da Nova Economia/Universidade Federal de Minas Gerais, Belo Horizonte, Brasil, pp. 11-47.

Gordon, Ian e Philip McCann (2000), "Industrial clusters, complexes, aglomeration and/or Social Networks?", Urban Studies, XXXVII (3), Sage, University of Glasgow, Glasgow, Reino Unido, pp. 513-532.

Haddad, Paulo Roberto (1999), "A competitividade do agronegócio e o desenvolvimento regional no Brasil: estudos de clusters", in Paulo Roberto Haddad (ed.), A competitividade do agronegócio-estudo de cluster, CNPq-Embrapa, Brasília, Brasil, pp. 23-36. 
Held, James (1996), "Clusters as an economic development tool: beyond the pitfalls", Economic Development Quarterly, X (3), Sage, Londres, Inglaterra, pp. 249-261.

Hofe, Rainer vom e Ke Chen (2006), "Whither or not industrial cluster: conclusions or confusions?", The Industrial Geographer, IV (1), Ephraim, Utah, Estados Unidos da America, pp. 2-28.

INE (Instituto Nacional de Estatística) (2015), "Dados estatísticos", Instituto Nacional de Estadística, Statistics Portugal, Portugal, $<$ www.ine.pt>, 25 de outubro de 2015.

Isaksen, Arne (1996), “Towards increased regional specialisation? The quantitative importance of new industrial spaces in Norway, 1970-1990", Norwegian Journal of Geography, L (2), Taylor and Francis online, Londres, Inglaterra, pp. 113-23.

Jackson, Julie e Peter Murphy (2006), "Clusters in regional tourism-an Australian case", Annals of Tourism Research, XXXIII (4), Elsevier BV, Amsterdã, Holanda, pp.1018-1035.

Kitson, Michael, Ron Martín e Peter Tyler (2004), "Regional competitiveness: am elusive yet key concept?", Regional Studies, 38 (9), Taylor and Francis online, Londres, Inglaterra, pp. 991-999.

Kumral, Nese e Çagaçan Deger (2006), "An industrial cluster study: as a basis for the Aegean Region's Development Policy", working paper núm. 06/01, Department of Economics of Ege University, Izmir, Turquia.

Lyon, Fergus e Andrew Atherton (2000), A business view of clustering: lessons for cluster development policies, Foundation for SME Development/University of Durham, Durham, Reino Unido.

Malerba, Franco (2004), Sectoral systems of innovation: concepts, issues and analyses of six major sectors in Europe, Cambridge University Press, Cambridge, Londres.

Malmberg, Ander (2003), "Beyond the cluster-local milieus and global connections", in J. Peck e W. Yeung (eds.), Remaking the global economy-economic-geographical perspectives, Sage, Londres, Inglaterra, pp. 145-59. 
Malmberg, Ander (1997), "Industrial geography: location and learning”, Progress in Human Geography, 21 (4), Sage Journals, Manchester, Inglaterra, pp. 573-582.

Malmberg, Ander e Peter Maskell (2002), "The elusive concept of localization economies: towards a knowledge-based theory of spatial clustering", Environment and Planning A, núm. 34, Sage Journals, Vancouver, Canada, pp. 429-449.

Malmberg, Anders e Peter Maskell (1997), “Towards an explanation of regional specialization and industry agglomeration", European Planning Studies, V (1), Taylor and Francis online, Londres, Inglaterra, pp. 25-42.

McRae-Williams, Pamela (2004), "Wine and tourism: cluster complementarity and regional development", en Smith, K.A. e Schott, C. (eds.), Proceedings of the New Zealand tourism and hospitality research conference 2004, Wellington, Nova Zelândia, pp. 237-245.

Martin, Ron e Peter Sunley (2003), "Deconstructing clusters: chaotic concept or policy panacea?", Journal of Economics Geography, 3 (1), Oxford University Press, Oxford, Inglaterra, pp. 5-35.

Marshall, Alfred (1890), Principles of Economics, MacMillan, London, Inglaterra.

Maskell, Peter e Anders Malmberg (1999), "Localised learning and industrial competitiveness", Cambridge Journal of Economis, 23 (2), Cambridge Political Economy Society, Oxford, Inglaterra, pp. 167-185.

Miller, Paul, Ron Botham, Hervey Gibson, Ron Martin e Barry Moore (2001), Business clusters in the U.K-A first assessment. Report for the Department of Trade and Industry. A consortium led by Trends Business Research, Department of Trade and Industry, Londres, Grã Bretanha

Natário, Manuela, Ascensão Braga e Constantino Rei (2011), "Clustering craftwork activities: an approach to promote regional development in a Peripheral Region of Portugal”, Investigaciones Regionales, núm. 19, Associación Espanhola de ciência Regional, Barcelona, Espanha, pp. 97-116. 
Neto, João Amato (2000), Redes de cooperação produtiva e clusters regionais: oportunidades para as pequenas e médias empresas, Atlas, São Paulo, Brasil.

OCDE (Organização de Cooperação e Desenvolvimento Económico) (1999), Boosting Innovation: The Cluster Approach, OCDE Proceedings, Paris, França.

OECD (Organization for Economic Co-operation and Development) (2005), Oslo Manual: guidelines for collecting and interpreting innovation data, OECD Publishing, Paris, França.

Pereira, Elisabeth da Costa (2011), "Clusters industriais e sistemas de inovação: o caso da Marinha Grande”, dissertação mestrado, Universidade de Aveiro, Aveiro, Portugal.

Pereira, Elisabeth Teixeira e António Jorge Fernandes (2006), "The clusters development as a factor of competitive advantage", International Journal of Entrepreneurship and Small Business, III (2), Inderscience Publishers, Olney, Reino Unido, pp. 266-276.

Pereira, Raquel Susana da Costa (2009), "Convergência vs divergência na Uniáo Europeia: os casos da Regiáo Norte de Portugal e da Galiza em Espanha”, tese de doutoramento, Departamento de Fundamentos de Análise Económica, Universidade de Santiago de Compostela, Galicia, Espanha.

Pinheiro, Alessandro Maia, Luiz Sobreira, Gomes Marden e Márcia Siqueira Rapini (2008), "Aglomeraçóes produtivas no Estado do Pará: uma proposta de análise para a construçáo civil”, Revista Brasileira de Gestão e Desenvolvimento Regional, IV (1), Universidade de Taubaté, São Paulo, Brasil, pp. 24-56.

Porter, Michael (1998), "Clusters and the new economics of competition", Harvard Business Review, LXXVI (6), Harvard Business Publishing, Cambridge, Estados Unidos da America, pp. 77-90.

Porter, Michael (1994), Construir vantagens competitivas em Portugal, Edição do Fórum para a Competitividade-Monitor Company, Lisboa, Portugal. 
Proinov (Programa Integrado de Apoio à Inovação) (2002), Presidência do Conselho de Ministros, Proinov, Lisboa, Portugal.

QREN (Quadro de Referencia Estratégica Nacional) (2007-2013), "Quadro de Referência Estratégico Nacional - Portugal 2007-2013”, Observatório do QCA III, Ministério do Ambiente, do Ordenamento do Território e do Desenvolvimento Regional, Lisboa, Portugal, <http://www.qren.pt/np4/home>, 22 de janeiro de 2015.

Rodrigues, Marcos Aurélio, Waleska de Fátima Monteiro, António Carlos de Campos e José Luiz Parré (2009), "Identificação e análise espacial das aglomeraçóes produtivas do sector de confecçóes na Região Sul”, XXXVII Encontro Nacional de Economia, Foz do Iguaçu, 8 e 11 de dezembro, Paraná, Brasil.

Roelandt, Teo y Pim den Hertog (1999), "Cluster analysis and cluster-based policy making in OECD countries: an introduction to the theme", in OECD Proceedings (ed.), OECD Boosting Innovation: the cluster approach, OECD Publications Service, Paris, França, pp. 9-23.

Russo, Antonio Paolo (2000), "The sustainable cultural cluster-notes on agglomeration, tourism policy and information technologies in tourist cities", paper prepared for the 40th Congress of the European Regional Science Association, 29 agosto-1 setembro, Barcelona, Espanha.

Santos, Cristina Cardoso Torres (2007), "Identificando clusters. Uma proposta metodológica com aplicação empírica ao sector do Turismo", tese de mestrado, Faculdade de Economia, Universidade do Porto, Porto, Portugal.

Silva, Carlos Alberto Vicente (2004), "Redes de cooperação de micro e pequenas empresas: um estudo das atividades de logística no setor metalúrgico de Sertãozinho - SP. 2004”, dissertação mestrado, Escola de Engenharia de São Carlos, Universidade de São Paulo, São Paulo, Brasil.

Silvestre, Bruno dos Santos e Paulo Roberto Dalco Tavares (2006), "As abordagens de clusters e de sistemas de inovação: modelo híbrido de análise de aglomeraçóes industriais tecnologicamente dinâmicas", 
Revista Gestão Industrial, 11 (4) Universidade Tecnológica Federal do Paraná-UTFPR Campus Ponta Grossa, Paraná, Brasil, pp. 99-111.

Simmie, James (2004), Innovation and clustering in the globalised international economy, Urban Studies, XLI (5-6), Carfax Publishing, Londres, Inglaterra, pp. 1095-1112.

Simōes, Rodrigo (2006), "Método de Análise Regional: diagnóstico para o planejamento regional", in Clélio Diniz e Marco Aurélio Crocco (org.), Economia Regional e Urbana: Contribuiçóes Teóricas Recentes, Universidade Federal de Minas Gerais, Belo Horizonte, Brasil, pp. 269-297.

Sölvell, Örjan, Christian Ketels e Göran Lindqvist (2008), "Industrial Specialization and Regional Clusters in the New EU Member States", Competitiveness Review: An International Business Journal, XVIII (1-2), Emerald Group Publishing Limited, Bingley, Reino Unido, pp. 104-130.

Suzigan, Wilson, João Furtado, Renato Garcia e Sergio Sampaio (2003), "Coeficientes de Gini Locacionais - GL: aplicação à indústria de calçados do Estado de Sáo Paulo", Nova Economia, XIII (2), Departamento de Ciências Económicas da Nova Economial Universidade Federal de Minas Gerais, Belo Horizonte, Brasil, pp. 39-60.

Recibido: 10 de enero de 2018. Reenviado: 14 de marzo de 2018. Aceptado: 2 de abril de 2018.

Ascensáo Maria Martins-Braga. Doutora em Gestão pela Universidade de Évora. Investigadora da Unidade de Investigação para o Desenvolvimento do Interior do Instituto Politécnico da Guarda. É professora no Instituto Politécnico da Guarda. Entre as suas últimas publicaçóes destacam-se, em coautoria, "Os Clusters e o desenvolvimento das regióes: cluster na cestaria em Gonçalo, uma realidade ou utopia”, Atas XXVI Jornadas Luso Espanholas de Gestão Cientifica, 3 a 6 de fevereiro, Idanha a Velha, Portugal (2016); "Padrões culturais e capacidade de inovação: um estudo de caso", XXV Jornadas Hispanolusas de Gestión Científica, 5 e 6 de fevereiro, Ourense, Espanha (2015); “O impacto socioe-conómico 
do Instituto Politécnico da Guarda na Economia Local", Revista Pecvnia, 18 (8), Universidad de León, Bernesga, Espanha, pp. 151-177 (2014).

Maria Manuela Santos-Natário. Doutora em Gestão pela Universidade de Évora. Investigadora da Unidade de Investigação para o Desenvolvimento do Interior do Instituto Politécnico da Guarda. É professora no Instituto Politécnico da Guarda. Entre as suas publicaçóes destacam-se, em coautoria, "Entrepreneurship in Frontier Regions: Study of Four Municipalities from BIN"; Revista de Estudios Regionales, núm 95, Facultad de Ciencias Económicas y Empresariales, Universidade da Malaga, Malaga, Espanha, pp. 15-38 (2015); "Dinâmicas de relacionamento nas Câmaras Municipais”, Economía, Sociedad y Territorio, XV (49), El Colegio Mexiquense, Toluca, México, pp. $723-746$ (2015); "O impacto socio-económico do Instituto Politécnico da Guarda na economia local”, Revista Pecunia, 18 (8), Universidad de León, León, Espanha, pp. 151-177 (2014); "Innovativeness Patterns in Different European Regions na Empirical Approuch", Studies Regional Sciences, 42 (3), The Japan Section of the Regional Science Association International, Azores, Portugal pp. 647-669 (2012).

Carla Alexandra Antunes-Ferreira. Mestre em Gestão pelo Instituto Politécnico da Guarda, "Emergência dos Clusters no âmbito do QREN: Análise dos Clusters Reconhecidos", tese de mestrado [em linha], Instituto Politécnico da Guarda, Guarda, Portugal, <http://bdigital.ipg.pt/dspace/ bitstream/10314/2196/1/GAP\%20\%20Carla\%20A\%20A\%20Ferreira. pdf $>, 20$ de abril de 2018. 